\title{
Numerically Thermo-Fluidic Analysis for Advanced Cooling Effects with Geometric Parameters in Electric Motors
}

\author{
Jonghyo Lee ${ }^{1}$, Namkwon Lee ${ }^{1}$, Sukkee Um² \\ ${ }^{1}$ Graduate School of Hanyang University \\ Seoul 04763, Republic of Korea \\ jonghyolee@ hanyang.ac.kr; namkwonlee@hanyang.ac.kr \\ ${ }^{2}$ Division of Mechanical Engineering, Hanyang University \\ Seoul 04763, Republic of Korea \\ sukkeeum@hanyang.ac.kr
}

\section{Extended Abstract}

Heat generated by the electric motors damages the components such as coils and magnets [1]. Researchers have thus been proposed various cooling systems for coil and magnet [2]-[4]. The cooling systems are divided into three types: aircooling, oil-cooling, water-cooling. Among them, the water-cooling type is applied to a high efficiency motor which generates high temperature like an electric motor of vehicle. However, the water-cooling pipe is far from the magnet, so it does not give a big cooling effect to the magnet. In this study, new cooling system designs have been proposed to cool both coils and magnets simultaneously. The heat and mass transfer characteristics of new geometries were numerically analyzed with computational fluid dynamics.

To cool the magnet efficiently, new rotor and stator designs were suggested to circulate the air inside the motor. Three geometrical effects on cooling performance were compared by the numerical analysis. First, eight channels were engraved in the rotor and stator to circulate the air flow inside the motor. The channels were drilled axially to blend the air on either side of the air gap. Second, the eight rectangular protrusions were emplaced on the outer surface of the rotor. Those are applied to the back of the channel entrance with respect to the direction of rotation, and the height is $1 / 3$ of the end coil. When the motor is operating, the air rotating around the axis flows into the channel by the protrusions. And then, the angle was extended to the channels and protrusions to induce the enhanced forced flow. The angles of the protrusions and channels are tilted in the direction of rotation about the center axis so that air can easily flow through the channels. The heat and mass transfer of the cooling design were analyzed with the parameters such as channels, protrusions, angles. The scale of variables was decided considering the durability of the motor components. The reference model is selected as a water-cooled $100 \mathrm{~kW}$ IPMSM motor without the inside air circulation.

In the cooling design with inclined protrusions and holes, the mass flow rate in channel was increased by $70.3 \%$ and the magnet temperature was $3.9 \mathrm{~K}$ lower than that of the reference model when operating at the rotation speed of 3,000RPM. And it leads to provide optimal cooling design guidance of the electric motors for the vehicle.

\section{References}

[1] G. D. Demetriades, et al, "A real-time thermal model of a permanent-magnet synchronous motor," IEEE Transactions on Power Electronics, vol. 25, no. 2, pp. 463-474, 2010.

[2] L. Alberti and B. Nicola, "A coupled thermal-electromagnetic analysis for a rapid and accurate prediction of IM performance," IEEE Transactions on Industrial Electronics, vol. 55, no. 10, pp. 3575-3582, 2008.

[3] C. C. Chang, et al, "Air Cooling for a large-scale motor," Applied Thermal Engineering, vol. 30, no. 11-12, pp. 13601368, 2010.

[4] L. Song, et al, "3D thermal analysis of water cooling induction motor used for HEV," Electrical Machines and System. 2008. International Conference on. IEEE, pp. 534-537, 2008. 